\section{A Case Report on the Development of a Humanitarian Pediatric Cardiac Surgery Programme at the Obafemi Awolowo University Hospital, ILE-IFE, Nigeria in Partnership with the Cardiaceye International Foundation Cardiovascular Team}

\section{Abstract}

Humanitarian cardiac surgeries consisting of highly specialized cardiovascular teams from developed countries can provide valuable local assistance with patient care in the emerging economies of the developing world. However, the best approach for developing a sustainable center in the emerging world is still debatable. Herein, we present a report a collaborative initiative between the Cardiac Eye International Foundation and the Obafemi Awolowo University, ILEIFE, Nigeria. The Cardiac Eye International Foundation is an independent non-profit charitable organization whose primary aim is to provide educational information, collaborate in scientific research and provide outreach training services for heart health care.

Keywords: Cardiovascular surgical procedures; Developing countries; International cooperation; Medical missions; Education; World health

Received: September 15, 2016; Accepted: September 22, 2016; Published: September 28, 2016

\section{Introduction}

As per the World Health Organization (WHO), at least eight neonates out of a thousand surviving neonates suffer from congenital heart disease (CHD) [1]. Unfortunately, about $80 \%$ of the cases require an operation within the first six months of life. Cardiac surgery imposes a huge burden on limited healthcare resources and is therefore not available in most Sub-Saharan countries. Where it is available, surgery is performed in small numbers due to financial constraints and shortage of human resources. Therefore, several countries are running collaborative programs between local institutions and teams from Europe and America, mostly sponsored by local or international nongovernmental organizations [2].

Of major concern is that in Africa, the Middle East and parts of Asia, the incidences of congenital CHD are rising and yet the infrastructure is inadequate to treat these children. We estimate that there are hundreds of thousands of children who are born pressure [1-3].

\section{Bashir M. Matata ${ }^{1,2}$, Uvie Onakpoya ${ }^{3}$, Akin Ogunrombi ${ }^{3}$, John Akintunde Okeniyi ${ }^{4}$ and Maqsood M. Elahi ${ }^{1}$

\author{
Heart and Lung Research Institute, \\ Cardiac-Eye International Foundation, \\ Texas, USA \\ 2 Cardiac Eye International Foundation \\ Africa, Mombasa, Kenya and Institute of \\ Infection and Global Health, University \\ of Liverpool, UK \\ 3. Department of Cardiothoracic Surgery, \\ Obafemi Awolowo University Teaching \\ Hospital, Ile Ife, Nigeria \\ 4. Department of Paediatric cardiology, \\ Obafemi Awolowo University Teaching \\ Hospital, Ile Ife, Nigeria.
}

\section{Corresponding author: Maqsood Elahi}

巨"manzoor_elahi@hotmail.com

Heart and Lung Research Institute, Cardiac Eye International Foundation, Texas, USA.

Tel: +44 (0) 792-901-0164

Citation: Matata BM, Onakpoya U, Ogunrombi A, et al. A Case Report on the Development of a Humanitarian Pediatric Cardiac Surgery Programme at the Obafemi Awolowo University Hospital, ILE-IFE, Nigeria in Partnership with the Cardiaceye International Foundation Cardiovascular Team. J Univer Surg. 2016, 4:3.

annually with surgically treatable CHD but unfortunately, millions are living with untreated, correctable disease [3]. Most of these children die by the age of 20 from the effects of prolonged cyanosis, pulmonary hypertension, and increased left ventricular

We believe that humanitarian missions consisting of highly specialized cardiovascular teams from developed countries can provide valuable local training and assistance with patient 
care. Interventional and corrective surgical procedures can be performed and potentially save the lives of patients with no alternatives. In order to provide the tools for a safe and highquality cardiovascular care, humanitarian mission groups need to recognize local needs and inherent challenges. They would need to triage appropriately in order to recognize the local and visiting team's limitations.

Teamwork is particularly important in cardiac surgery, because the weakest link can determine the ultimate results. A star surgeon cannot perform without adequate support from anesthesia, perfusion, and postoperative care, or without a precise preoperative diagnosis. This team approach renders training in the specialty difficult in countries where there are no established or experienced training centers. We believe that there is need for more foreign aid to assist developing countries implement such local resources. However, internationally, there is less political will from donor countries to support such initiatives.

An alternative approach is through humanitarian collaboration teams. Humanitarian collaboration cardiac surgery teams should be supported to make regular and frequent visits to a selected center in developing countries and perform surgery with the aid of local specialists. This would be an excellent way of transmitting knowledge and skills within developing countries. This manner of training has the further advantage of giving immediate highquality care to the local population, which is usually desperately needed, because there is often a huge backlog of patients.

However, to date, there has been no organized, sustained effort to improve treatment for these patients through training of local staff within their communities. The Heart-Lung and Research Institute, Cardiac Eye International Foundation (CEIF) has dedicated most of its resources to developing prototype centers around the world that would address these problems. Cardiac Eye International Foundation is an independent nonprofit organization that is dedicated to work with physicians, technicians, intensive care professionals and surgeons, to provide a technical infrastructure that can support information exchange, collaboration, administration and a richly interlinked platform for major health care activities around the world. The primary goal of CEIF is to improve care for children with CHD and increase the number of children receiving adequate care within the region. In this regard, we report our first ever mission of this kind at Obafemi Awolowo University, ILE-IFE, Nigeria. We describe the specific challenges faced, how we addressed them and our attempt to develop sustainable cardiovascular care within this region.

\section{Location of mission}

The CEIF Nigeria project was held in the Obafemi Awolowo University Teaching Hospital Complex, OAUTHC, lle Ife, Osun State, and performed successful pediatric open heart surgeries on six children including ventricular septal defect repairs, atrial septal defect repairs, tetralogy of fallot repair and mitral valve replacement. The children hail from various parts of the country including Ilesa and Ikire in Osun State, Akure (Ondo State), Warri
(Delta State), Offa (Kwara State) and Port- Harcourt (Rivers State) and the operations were carried out between April $26^{\text {th }}$ and May $1^{\text {st }}$ 2016. The mission was a success largely due to the understanding between the Hospital and the Cardiac Eye Foundation International team headed by Professor Maqsood Elahi who is a pediatric and adult Cardiac Surgeon. Professor Elahi also noted that the congenital heart disease problem was currently rampant in the country with new cases of this type of heart disease discovered every day in many young patients. The medical team and the hospital management deserve hearty congratulations for their immense efforts and huge financial commitments to enabling these children successfully receive their surgical treatments locally.

\section{Teamwork}

Professor Maqsood Elahi made an exploratory visit six months before the planned mission to establish contacts with the University to ensure local support from within the university, governmental and nongovernmental sources. During this visit, local experiences and knowledge were assessed together with the availability of equipment. A long-term project was proposed for a duration dependent upon the level of local expertise, and a team of fully trained specialists was proposed for regular visits, the composition of the team depending on the local needs.

The local team included Dr. John Akintunde Okeniyi, the pediatric cardiologist, Dr. Uvie Onakpoya and Dr. Akin Ogunrombi the cardiothoracic surgeons, who selected and obtained patient's consents for surgery under the leadership of Professor Elahi. The proposed cardiovascular surgical team, for the mission, was made up of a surgeon, an anesthetist, a perfusionist, a scrub nurse, an intensive care nurse or a respiratory therapist (or both), and a physical therapist. Our team was the only foreign visiting team training the local staff (Figure 1).

\section{Frequency}

Following the success of the first mission, it was jointly decided with the local authorities that the CEF team will make at least 4 visits a year usually lasting up 10-12 days duration. With this frequency, the local staff would have time to admit patients and follow them up after the departure of the visiting team. This frequency also enabled the local team to build on the techniques and routines, which is not the case if visits are too far apart.

\section{Caseload}

There is need for sufficient number of cases to be operated during these visits if the local staffs are to acquire sufficient training and expertise to operate fully independently. However, although there is a huge backlog of cases, financing the operations for so many patients is hugely problematic. At ILE-IFE, for example, our foundation supported the cost of diagnostic procedures and surgical treatment such that all the patients were operated free of charge. Patients were screened through regular contacts and meetings with the local diagnostic team. In the initial project visiting of 2 cardiac cases were scheduled for operations daily. We believe that in the subsequent visits, there will be an increase 


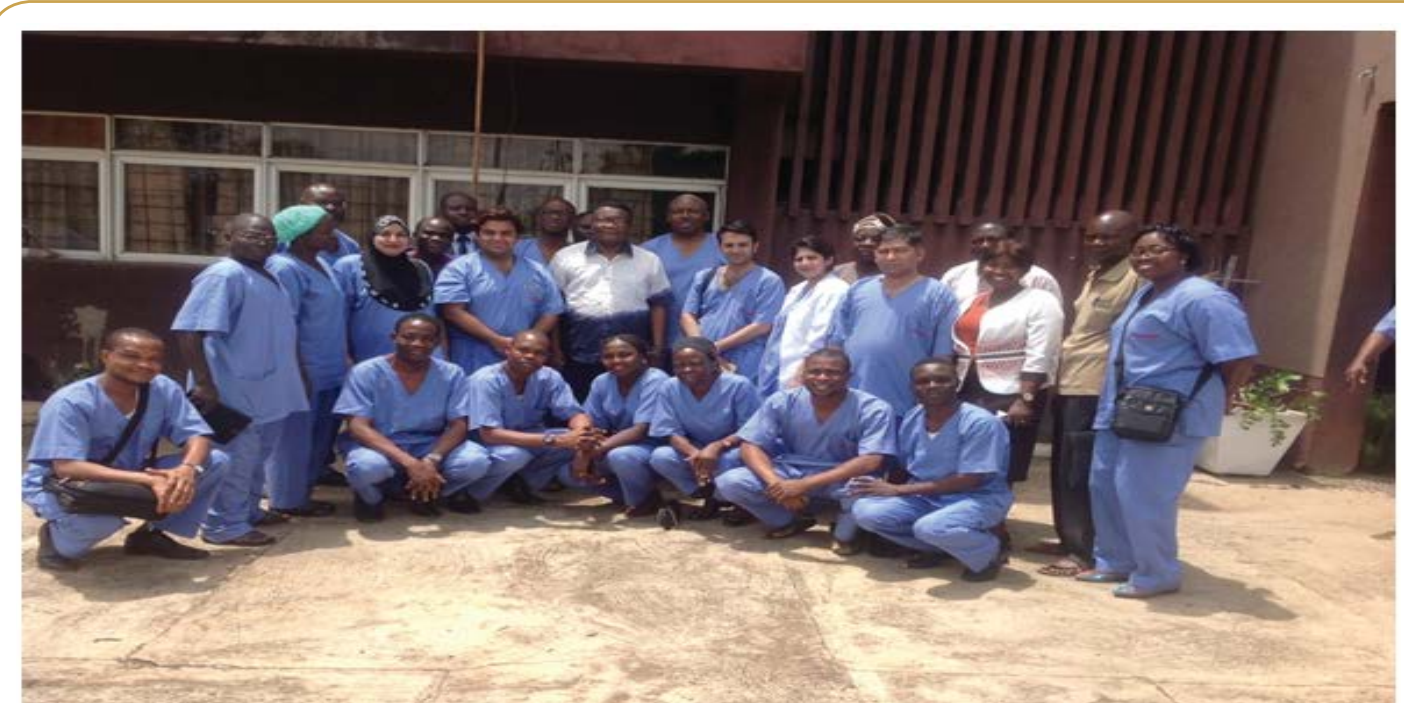

Figure 1 The team (Professor Maqsood Elahi and the local and international staff) with the Professor VA Adetiloye, Chief Medical Director OAUTHC.

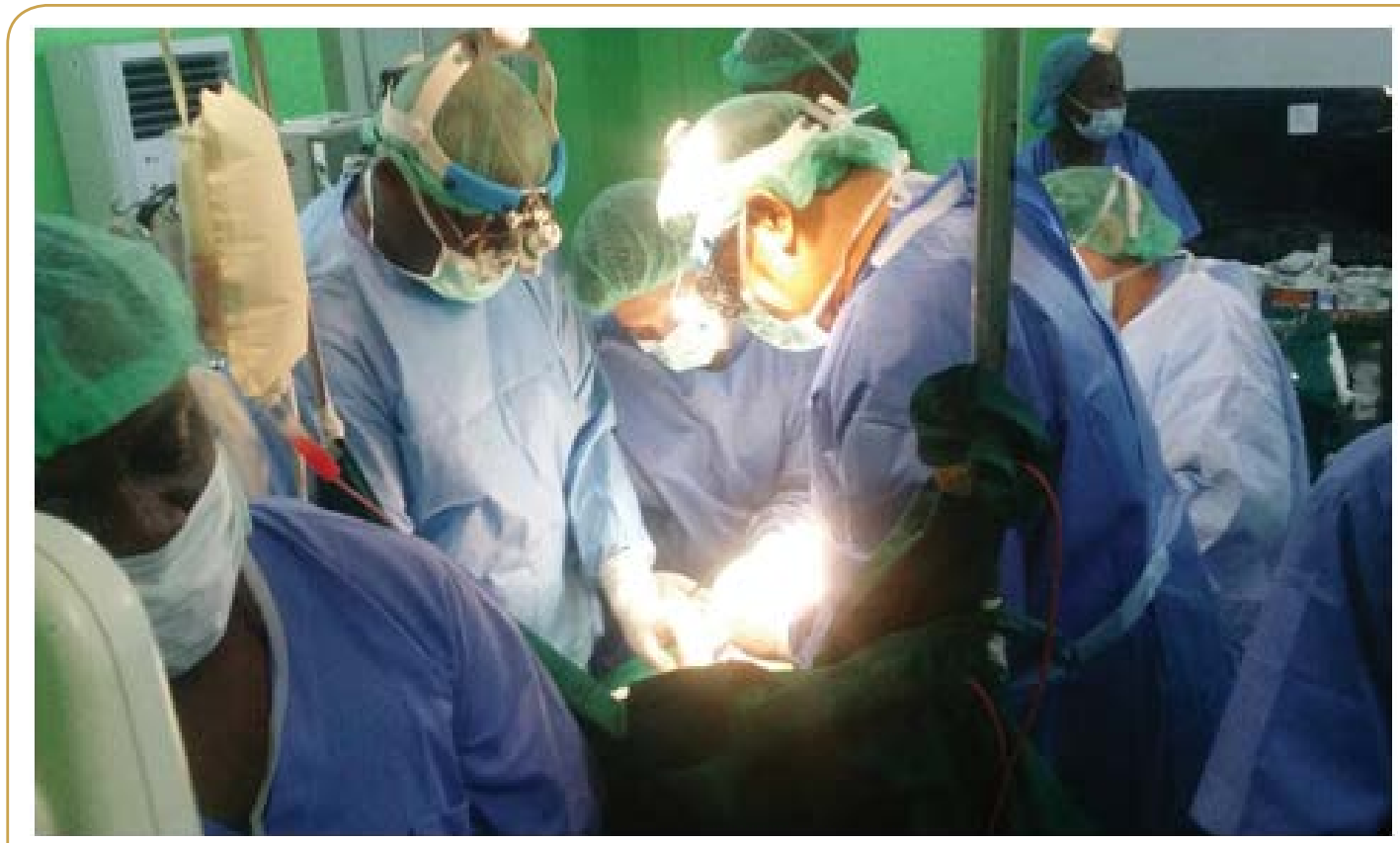

Figure 2 Professor Maqsood Elahi operating with the Cardiac Eye International Foundation on a child who required Tetralogy of Fallot Repair.

in skills and knowledge which would allow a third or even a fourth case to be operated in a day. However, the teaching process requires time, whereby excessive caseloads would be deleterious to the teaching process. Therefore, it was agreed that each $10-$ day mission should operate on 10 cases to 12 cases which would allow time for bedside rounds, teaching, and meetings with the cardiology staff to review newly diagnosed cases for future visits (Figure 2).

\section{Objectives}

Present study was done for knowing the trends, presentation of cases of primary vaginal cancer in women from low resources settings.

\section{Equipment}

Investment on equipment was made by the local hospital or government authorities. Disposable materials were purchased by the local hospital administration and the visiting team offered advice on how and where to obtain the best value for money. This enabled the local teams to obtain the necessary cardiologic, anesthetic, and surgical material for daily use and choice of equipment. Donations for used equipment came from hospitals and companies with which contacts were established through the CEIF center. The local king of the ILE-IFE supported the project sponsoring the costs of some of the operations. The International College of Surgeons-US section also supported the CEIF team undertaking the cardiac surgery project in ILE-IFE. 
With time we also realized that it is not always beneficial for the purpose of teaching and knowledge transfer to make projects totally free of charge. This contrasts the past practices by some experienced foreign physicians operating in other countries where they encouraged by the local authorities to provide free surgeries but without any teaching to the local teams. We now work as joint venture between the local government, the hospital and our foundation, whereby a minimal fee is charged to the patients in line with local standards.

\section{The experience of the CEIF team}

The CEIF team made its way to Lagos Murtala Muhammed Airport on the April $24^{\text {th }}, 2016$ flying over the Sahara Desert. On our arrival we found the weather in Lagos to be rather hot as we were going through the immigration clearance. Our hosts were already there at the airport to receive us. We then travelled to ILE-IFE where we were given a warm welcome by our hosts at the university guest house.

Next morning, we visited the pediatric cardiac ward and attended the patients who were listed for surgery. Then we went to the physical therapy department where they had planned for lectures. We were introduced to all the therapists and the head of department Prof. Rufus Adetiyole and discussed the program agenda. Subsequently, we were introduced to the hospital administration staff and doctors. Then we visited the intensive care unit (ICU) and the operating room. In the afternoon, together with the local teams we prepared the theaters with all necessary perfusion equipment including the heart lung machine, hypothermia machine, ACT machine \& blood gas analyzer. All the cannulae, oxygenators and hemofilters for pediatric patients were checked. In the evening, we returned to the guest house, had dinner and then discussed all patients that were planned for surgeries the next day (Figure 3).

The first patient was a 7 months old male baby, who had large OS-ASD. The surgery was started late as everyone had to get ready for the first case in the history of the institution. Surgery went well and the defect was closed with a pericardial patch. The patient was transferred to the ICU and extubated early morning the next day. Our other surgeries also went well. We were all very pleased to see all the patients successfully recover post-operatively in the pediatric ICU. A summary of the patients, surgeries and outcomes are presented in Table 1.

In addition to performing the surgeries the team was also involved in teaching and training from the nursing perspective to ICU management, perfusion and physical therapy (Figure 4).

Our host, Dr. Onakpoya took us to visit a local TV station in the town. Then we visited the King palace which was magnificently built including court of law. After that we visited various

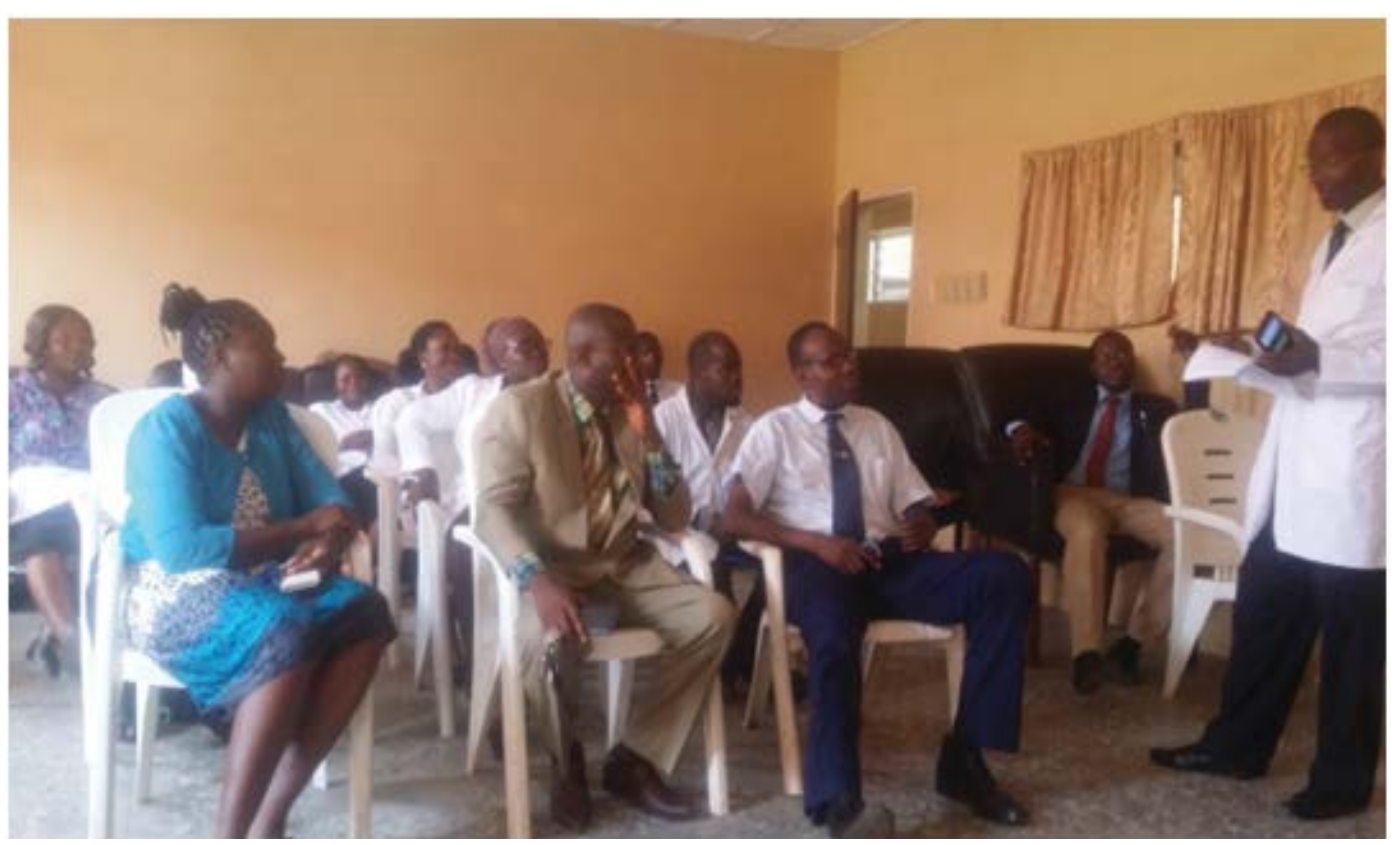

Figure 3 The local class room for training the local medical professionals.

Table 1 List of patients operated upon at the Obafemi Awolowo University Teaching Hospital, ILE-IFE, Nigeria between April $26^{\text {th }}$ and May $1^{\text {st }}, 2016$.

\begin{tabular}{|c|c|c|c|c|c|c|}
\hline S. No. & Age & Sex & Weight (kg) & Height (cm) & Diagnosis & Surgery performed \\
\hline 1 & 6 months & $\mathrm{M}$ & 6.3 & 58 & Large ASD & ASD closure \\
\hline 2 & 11 months & $M$ & 5.6 & 64 & Large ASD & ASD closure \\
\hline 3 & 11 years & $\mathrm{F}$ & 25.7 & 140 & RHD+Severe MR & Mitral valve replacement \\
\hline 4 & $5+$ years & M & 12 & 95 & TOF & Total correction \\
\hline 5 & $1+$ years & M & 10 & 76 & VSD & VSD Closure \\
\hline 6 & 3 years & $M$ & 11.7 & 91 & Large PM VSD & VSD closure \\
\hline
\end{tabular}


University departments and admired some of the building with uniquely structured architecture (Figure 5).

We had an off day the next day as we finished surgeries. After visiting patients in ICU, we made our way to the university administration hall for a press conference with the local media. The Chief Medical Director, Prof. VA Adetiloye chaired the meeting. He was very appreciative of everyone's effort in making the mission a success. He gave a comprehensive review of what we had done, talked about the future plans and thanked all for their hard work and commitment. Then Professor Maqsood Elahi introduced the Cardiac Eye International Foundation team, presented his views about development of cardiac surgery on Humanitarian basis all around the world and gave his future plan on how to develop a fully-fledged cardiac surgery department in this university. A group photograph with Chief Medical Director was taken. All attendees were very pleased for the successful outcome of the surgeries.

\section{Discussion}

Humanitarian medical missions can be personally rewarding, provide immediate high-quality surgical care and create an important educational opportunity for all involved. The patients benefit substantially in their quality of life and in short- and longterm survival. Such medical missions can foster the development of bilateral links that allow the host team to develop a large resource base with the visiting medical team. We feel that volunteer missions can help to achieve both short- and long-term goals by providing comprehensive care to the individuals assessed on each mission. Barriers, such as communication challenges, limited organizational support, lack of coordination and personal unpreparedness, can be overcome. Most importantly, we feel that volunteer missions can help provide the local medical team with the education and tools needed to deliver muchneeded care to the population at large. Creating sustainable benefits from humanitarian missions and placing a strong emphasis on education for all members of the cardiovascular team was a critical element of our Foundation. The local team was eager to learn, so we provided daily interactive educational sessions on many aspects of patient care, including preoperative assessment, intraoperative surgical and anesthetic procedures, and postoperative critical care.

We conducted extensive teaching sessions with the local surgical team about operative conduct, procedural details and avoiding complications and a commitment to follow up care. We plan to make in future at least 4 visits each year. During the visits we are plan to invite cardiologists and other cardiac surgery specialist to make the visit alongside the Cardiac Eye International Foundation team which could provide further educational opportunities for the local team.

\section{Conclusion}

We feel that cardiovascular health care professionals from developed centers must continue to increase efforts to assist with international health initiatives to support centers in the developing world. The burden of cardiovascular disease is increasing, and without such assistance this will become an important health issue in the decades to come. Whereas humanitarian missions have limitations, they can provide substantial health care benefits to those treated and can provide the educational framework to help many local physicians care for their own future patients. These missions must be properly structured to create sustainable improvements in cardiovascular outcomes. In describing our experience, we hope to instill in others the same passion for international surgery initiatives and raise further awareness of the increasing incidence of cardiovascular disease in developing countries.
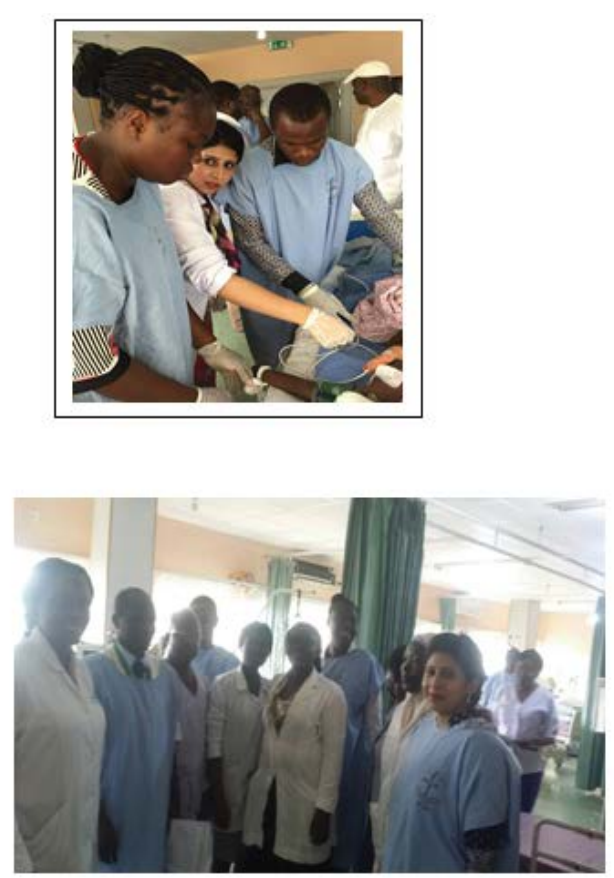
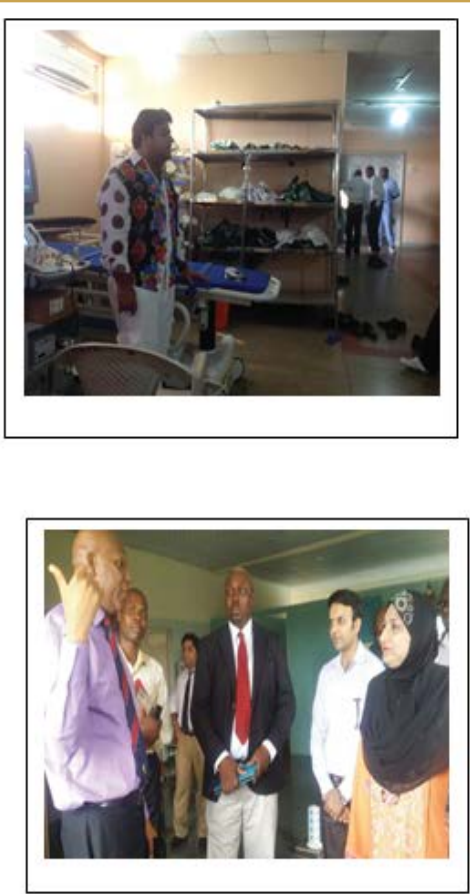

Figure 4 The CEIF team remained involved in teaching and training nurses, to ICU management, perfusion and physical therapy. 

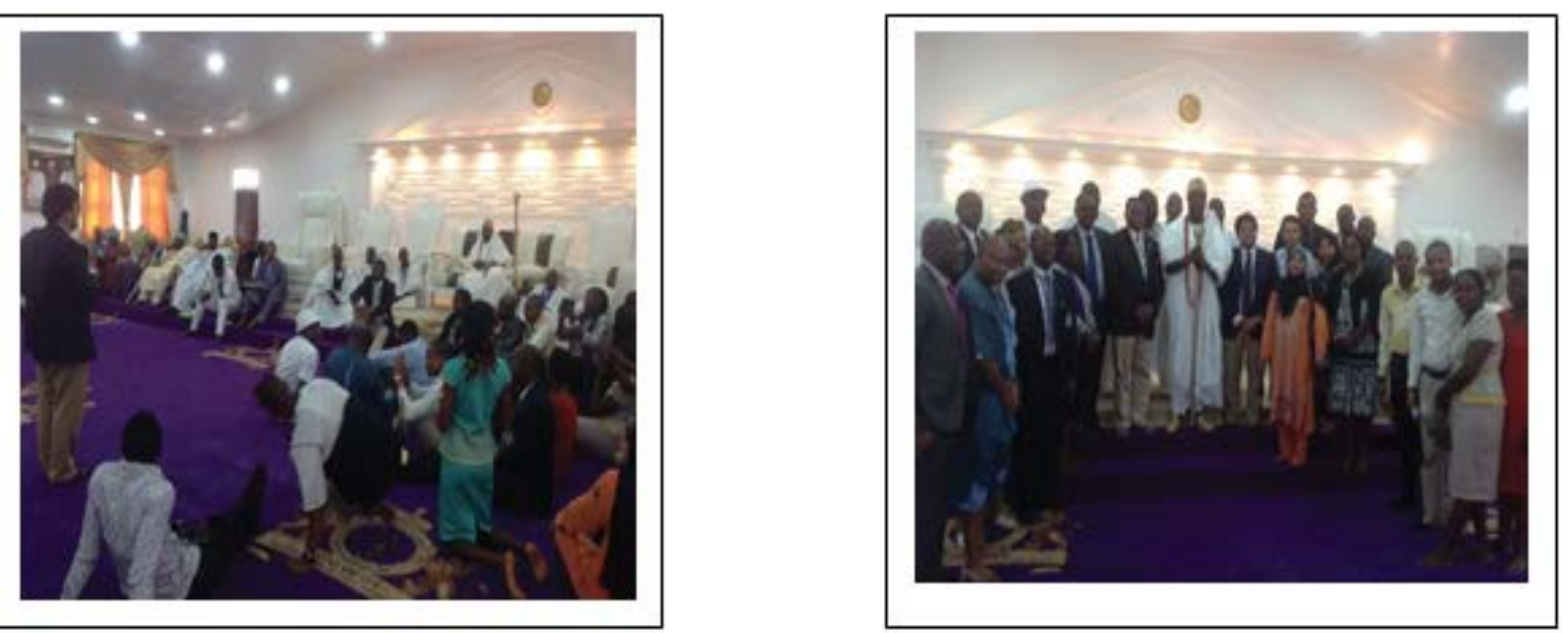

Figure 5 Professor Maqsood Elahi thanking His Majesty the King Adeyeye Enitan Ogunwusi of Osun State and introducing his CEIF team. At the end of the ceremony the CEIF and university team had a group photo with the King.

\section{Acknowledgements}

Local accommodations and transportation with air flights were provided by the OAUTHC. Valve prosthesis, graft material and cardiopulmonary bypass components were generously donated by Medtronic and King Adeyeye Enitan Ogunwusi of Osun State.
We thank The International College of Surgeons-US section for their timely and kind support.

\section{Contributors}

CEIF Team: Mr. Asif Mushtaq (Chief Perfusionist), Dr. Zilehumma (physical therapist), Ms. Samina Kauser (senior scrub nurse), Dr. Waqas Afzal (Chief resident). 


\section{References}

1 Ghosh P (2005) Setting up an open heart surgical program in a developing country. Asian Cardiovasc Thorac Ann 13: 299-301.

2 Velebit V, Montessuit $M$, Bednarkiewicz M, Khatchatourian G,
Mueller X, et al. (2008) The Development of Cardiac Surgery in an Emerging Country. Tex Heart Inst J 35: 301-306.

3 Elahi MM, Matata BM (2016) Cardiac Surgery for Communities in Need - Meeting the Continuous Challenges for Delivering New Models of Global Humanitarian Health Programmes. MOJ Surg 3: 00033. 